\title{
Povidone-lodine Hookah Therapy for the Treatment of COVID-19 and other Respiratory Viruses: A Hypothesis we must Test
}

\author{
Raj K. Gandhi
}

Department of Surgery, Honorary Thoracic Surgeon, Emory Johns Creek Hospital, Atlanta, Georgia

Address for correspondence: Raj K. Gandhi, 4553 N Shallowford Road, Suite 70-C, Atlanta, GA 30338, USA. E-mail: rajkgandhi101@gmail.com

I would like to make a strong case and suggest a new indication for an old drug which has been known for its strong bactericidal and virucidal properties. The drug is povidone-iodine (PVP-I). It has been used extensively over a long period of time as a strong antiseptic agent in different forms. In all these forms, it is used as a topical agent and has been found very efficacious and safe. ${ }^{[1-11]}$

In the most common form, PVP-I is used as a surgical scrub and/or a surgical prep for sterilizing the skin for a major or minor surgical operation or some other invasive procedures such as local injection, aspiration, or cardiac catheterization. A $10 \%$ solution is used extensively for surgical prep and causes minimal skin irritation, especially when residual paint is washed off at the completion of the procedure. It is also used commonly as an overthe-counter agent for treating minor wounds and burns. 5\% betadine (PVP-I) ointment is also used for this purpose and it acts as an effective antiseptic agent without any injurious or untoward effect on the skin.

PVP-I is used to sterilize the conjunctiva and cornea in the eye for cataract surgery. It is also used as an eye wash as a cleansing and antibacterial agent after accidental exposure to potential contaminants. It is used by dentists and oral surgeons to cleanse and sterilize the mucosal lining in the oropharyngeal cavity and on the gums. It is used by ENT surgeons to cleanse and sterilize the skin and mucosa in the nose and nasopharynx. Urologists and OBGYNs use PVP-I solution or ointment to apply to urogenital skin and mucosa as a sterilizing and antibacterial agent. It is also used as a vaginal douche by women.

Intraoperatively, PVP-I solution has been extensively used by general surgeons to cleanse and wash heavily contaminated peritoneal cavity due to general peritonitis resulting from perforated viscus.
They very frequently cleanse the cut edges of the transected bowel with PVP-I soaked swabs with the intention of not only cleaning but sterilizing them before reanastomosis to ensure good healing and minimize the chances of local infection and anastomotic leak.

Thoracic surgeons wash pleural cavity with PVP-I solution after pulmonary and esophageal resections and clean the cut edges of bronchi and esophagus with betadine solution before performing anastomosis. In case of empyema or subphrenic abscess, they use copious amounts of PVP-I solution to clean and disinfect these cavities after proper drainage. During pulmonary resections, they frequently use betadine soaked gauze to temporarily cover the cut surface of the lung. About 10\% PVP-I solution apparently causes no chemical injury to the cut surface of the pulmonary parenchyma or pleura.

lodine has a strong bactericidal, sporicidal, fungicidal, protozoacidal, and virucidal properties. Most bacteria are killed within 10 min by $0.0002 \%$ solution and in $10 \mathrm{~s}$ by $1 \%$ solution. In PVP-I, iodine is complexed with the pyrrolidone nitrogen of polyvinyl-pyrrolidone. In 10\% PVP-I which contains $1 \%$ available iodine, the free iodine concentration is only 8 micromoles ( $0.001 \%$ free iodine). When PVP-I is diluted to $0.1 \%$, the free iodine concentration rises to 80 micromoles because of dissociation of the complex. Bactericidal activity is thus higher at $0.1 \%$ than at $10 \%$ concentration. ${ }^{[11]}$

Topically applied, PVP-I can kill bacteria and viruses very fast - within a matter of seconds - without causing any apparent injury to the skin, mucous membranes, or serosal surfaces such as pleura and peritoneum. It is not injurious to conjunctiva or cornea either. Pharmacologically speaking, a very dilute solution with low concentration of PVP-I has stronger bactericidal and virucidal effect. ${ }^{[11]}$

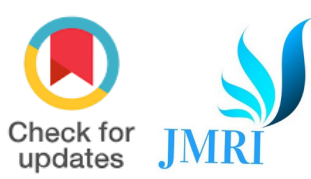

How to cite this article: Gandhi RK. Povidoneiodine hookah therapy for the treatment of COVID-19 and other respiratory viruses: A hypothesis we must test. J Med Res Innov. 2021;5(1):e000258.

DOI: 10.32892/jmri.258

Publication history:

Received: 23-01-2021

Accepted: 08-02-2021

Published: ***

Editor: Dr. Varshil Mehta

Copyright: Gandhi RK, This is an open-access article distributed under the terms of the Creative Commons Attribution License CC-BY 4.0., which permits unrestricted use, distribution, and reproduction in any medium, provided the original author and sources are credited.

Funding: NIL

Conflict of Interest: NIL

MK Medkrux 
Based on all this, I conjecture to hypothesize that air actively inhaled through a very dilute solution of PVP-I (similar to a hookah) will be effective in killing the coronavirus (CoV)- 2 without causing any significant injury to tracheobronchial tree or lung alveoli. This mode of application will essentially be topical in nature. If there is a chemical injury, it will be minor and reversible in my opinion. There will be some possible absorption from the alveoli into the blood, but the dose will be so small that it should cause no systemic effect or toxicity. ${ }^{[4,5]}$

In the following paragraphs, I will describe the dosage and the method of instituting this treatment as I see fit at this moment. With time and experience, we will learn more and make necessary adjustments and/or modifications.

Povidone-iodine hookah will consist of a small bottle or flask with a stopper with two holes. Through one hole, a small tube will enter and go down to just above the bottom of the bottle. This tube will be called air tube and its upper end will be just above the stopper. The second tube will be called hookah tube and it will enter the bottle through the second hole in the stopper, and it will project into the bottle for only a centimeter or two below the stopper. Its outer end will be connected to a flexible tube (preferably made of polyethylene) with a mouth piece at its end similar to that of a hookah.

The hookah bottle will be filled up to about onethird capacity with $1 \%$ PVP-I solution using sterile water to make it. The air tube will be adjusted up or down to leave about $1 \mathrm{~cm}$ length submerged in the PVP-I solution. To use the hookah, you will first exhale fully and then hold the mouth piece between the lips tightly. Immediately, thereafter, you will suck the air from the hookah bottle with a deep inhalation. You will then hold the breath for a few seconds and exhale slowly through the nose. Then, you will repeat the process with a second deep puff and again hold the breath for a few seconds before slowly letting it out through the nose. A total of five puffs will make one dose. Someone suffering from COVID-19 who is able to breathe normally the total daily dosage will be one dose every hour or so during the day for a total of 10 doses. In most cases, a 4-5 days course of this therapy will be enough to kill the virus adequately. In some cases, 7 days treatment may be needed.

Now, the basis and the rationale of this dosage: An adult male normally has a tidal volume of about $500 \mathrm{~mL}$ at rest. With a deep puff, he will presumably inhale twice as much that is $1000 \mathrm{~mL}$. One cubic meter of air contains about $20 \mathrm{~g}$ of water at $100 \%$ relative humidity at room temperature. In other words, $1000 \mathrm{~L}\left(1 \mathrm{~m}^{3}\right)$ of air will hold about $20 \mathrm{~g}$ of water at $100 \%$ relative humidity. Hence, $1 \mathrm{~L}$ of air at $100 \%$ humidity at room temperature will contain $20 \mathrm{mg}$ of water. All the air being inhaled from the hookah bottle is coming through $1 \%$ PVP-I solution and should have $100 \%$ relative humidity. One liter of this air contains $20 \mathrm{mg}$ of water with 1\% PVP-I in it. That comes to $0.2 \mathrm{mg}$ of PVP-I in each hookah puff. Hence, five puffs will provide a total of $1 \mathrm{mg}$ of PVP-I. A total daily dosage of 10 hookah sessions will provide a total of $10 \mathrm{mg}$.

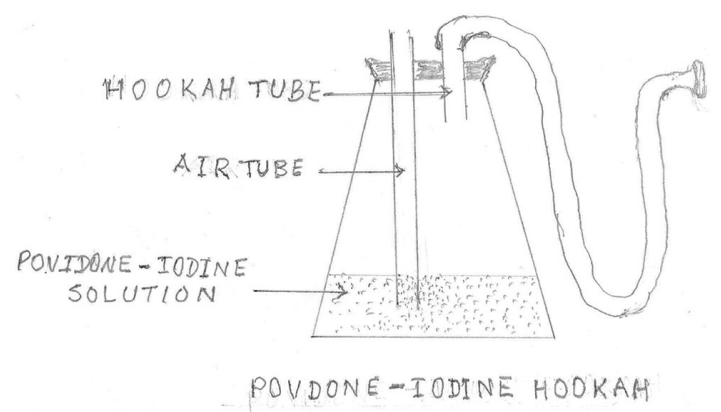

Inhaled air with each puff will in succession come in contact with the mucosal lining of mouth, pharynx, larynx, trachea, entire bronchial tree with its eight or nine generations down to terminal, and respiratory bronchioles and finally alveoli. Povidone-iodine dissolved in water molecules being carried by the inhaled air with $100 \%$ relative humidity will be very thinly painted on all these mucosal surfaces and finally the alveoli. It will either start killing the CoV or make it incompetent to multiply in all these areas. $^{[8]}$ During exhalation, the mucosal lining of nasopharynx and nose will be similarly painted with the residual amount of PVP-I. Five puffs, hopefully, will provide adequate amount of PVP-I to start the virucidal action, and 10 such sessions during the course of one day will be enough. A variation of this dosage schedule will be using 2\% PVP-I solution in the hookah bottle and taking five puffs every 2-3 $\mathrm{h}$ for a total of five sessions per day. To find a safe and effective dosage schedule, we will obviously need to try a few variations. In very sick patients on mechanical ventilation, a nebulizer will be used to deliver an appropriate dose through the endotracheal or tracheostomy tube.

Since there is no effective therapy for COVID-19, the hypothesis outlined above must be put to test as soon as possible. Safety studies can be performed in animals and/or human volunteers in a matter 


\section{Gandhi: Povidone-iodine hookah therapy}

of days or weeks and if this therapy is found to be safe, it can be put to clinical trials or even clinical use immediately.

Being a pathologist, a general surgeon and a thoracic surgeon and having used PVP-I in thousands of surgical cases over a period of 40 plus years, I feel fairly confident that my hypothesis will pass the test. If that happens, we would have found a simple and inexpensive therapeutic measure for COVID-19. Since I was convinced about the efficacy of this treatment, the only remaining question in my mind was about its safety. So I made a simple hookah using a glass bottle, 1\% PVP-I solution and two straws going through a make shift cellophane airtight lid. Then, I exhaled fully and took a deep puff of air from the straw coming out of the upper part of the bottle. I could hear the bubbling sound like in a hookah. For this puff, I used my nearly full inspiratory capacity and must have inhaled at least $2000 \mathrm{~mL}$ of air. After two or three normal breaths each time, I repeated the process for 4 more times thus making a total of five puffs during the course of 1-2 $\mathrm{min}$. This was twice the amount of dose recommended above. My oxygen saturation measured by a pulse oximeter before this exercise was 96-98\% and remained unchanged $1 \mathrm{~min}, 5 \mathrm{~min}$, $1 \mathrm{~h}$, and $4 \mathrm{~h}$ after this exercise. My heart rate also remained the same, $72-75 / \mathrm{min}$. These parameters showed no change in $24 \mathrm{~h}$ and I did not experience any untoward symptoms.

In view of the raging pandemic which has already claimed over 250,000 lives in the U.S. and close to 2 million lives worldwide, it is my recommendation that physicians taking care of patients with COVID-19 should give this treatment a try. I think that they have the discretionary authority to use medicines for "off label" indications under special circumstances, if in their opinion, potential benefits outweigh potential risks and the patient agrees. The Food and Drug Administration and similar health agencies in other countries should allow the use of this treatment under the umbrella of "Compassionate Use and/or Expanded Access Mechanism for Drugs." For very sick patients being maintained on ventilators, I would suggest nebulizer treatment with 1\% PVP-I solution for 2 min every 1-2 $\mathrm{h}$ depending on the extent of pulmonary involvement and adjust it up or down based on the response to this therapy. I must confess this dose recommendation is somewhat intuitive on my part. If PVP-I hookah therapy works, we would have found a new and inexpensive treatment for not only
COVID-19 but also quite possibly for many other respiratory infections caused by viruses, bacteria, and fungi. It will work just as well against the variants of CoV (severe acute respiratory syndrome CoV [SARS-COV-2]) and other mutated strains. Influenza caused by the flu virus should respond to this therapy equally well, as should many other respiratory infections.

The ease with which a working hookah bottle can be made and the availability of PVP-I all over the world will make it possible for physicians around the globe to successfully use this therapy for their patients. They will need to make sure that there is no mix up or confusion between the hookah tube and the air tube and that their patients will always inhale from the hookah tube and not the air tube. Accidental sucking from the air tube may cause aspiration of PVP-I solution into the lungs and severe pneumonia. This must be avoided at all costs. Patients who are allergic to iodine will not be able to use this treatment.

Vaccines for CoV, SARS-COV-2, have been made with unprecedented speed and are being rolled out as fast as humanly possible. It will still take many years to inoculate the entire population on the planet. We do not know how long the immunity will last after vaccination. Nor do we know if this virus will mutate or keep on mutating into new strains requiring new vaccines in the future. No one can predict about the eventual outcome of this pandemic or future epidemics caused by respiratory viruses. Having an effective antiviral therapy for respiratory viruses, therefore, is of paramount importance.

It behooves the physician and scientific community around the world to put the hypothesis presented above to test, and hopefully find in it, a cure for the devastating scourge being caused by the CoV (SARS-COV-2).

\section{References}

1. Eggers M, Eickmann M, Zorn J. Rapid and effective virucidal activity of povidone-iodine products against middle east respiratory syndrome coronavirus (MERS-CoV) and modified vaccinia virus ankara (MVA). Infect Dis Ther 2015;4:491-501.

2. Mady LJ, Kubik MW, Baddour K, Snyderman $\mathrm{CH}$, Rowan NR. Consideration of povidone-iodine as a public health intervention for COVID-19: Utilization as "personal protective equipment" for frontline providers exposed in high-risk head and neck and skull base oncology care. Oral Oncol. 2020;105:104724.

3. Aceves C, Anguiano B, Delgado G. The extrathyronine

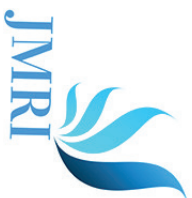




\section{Gandhi: Povidone-iodine hookah therapy}

actions of iodine as antioxidant, apoptotic, and differentiation factor in various tissues. Thyroid. 2013;23:938-46.

4. Dyck RF, Bear RA, Goldstein MB, Halperin ML. lodine/ iodide toxic reaction: Case report with emphasis on the nature of the metabolic acidosis. Can Med Assoc J 1979;120:704-6.

5. Cruz FD, Brown DH, Leikin JB, Franklin C, Eggers DO, Eickmann $\mathrm{M}$, et al. Iodine absorption after topical administration. Infect Dis Ther 2015;4:491-501.

6. Byrd OE, Malkin HM, Reed GB, Wilson HW. Safety of iodine as a disinfectant in swimming pools. Public Health Rep 1963;78:393-7.

7. Aillon KL, El-Gendy N, Norenberg JP, McDonald J, Dennis C, Berkland C. lodinated NanoClusters as an inhaled CT contrast agent for lung visualization. Mol Pharm 2010;7:1274-82.
8. Sriwilaijaroen N, Wilairat P, Hiramatsu H, Takahashi T, Suzuki T, Ito $M$, et al. Mechanisms of the action of povidone-iodine against human and avian influenza A viruses: Its effects on hemagglutination and sialidase activities. Virol J. 2009;6:124.

9. Kariwa H, Fujii N, Takashima I. Inactivation of SARS coronavirus by means of povidone-iodine, physical conditions and chemical reagents. Dermatology 2006;212 Suppl 1:119-23.

10. Kanagalingam J, Feliciano R, Hah JH, Labib H, Le TA, Lin JC. Practical use of povidone-iodine antiseptic in the maintenance of oral health and in the prevention and treatment of common oropharyngeal infections. Int J Clin Pract 2015;69:1247-56.

11. Brunton LL, Hilal-Dandan R, Knollmann BC. Goodman and Gilman's the Phamacological Basis of Therapeutics. $7^{\text {th }}$ ed. New York: lodophores; 1985. p. 965-6. 